\title{
Penciptaan Seni Pertunjukan Berbasis Penelitian
}

\author{
I Gusti Ayu Srinatih \\ Institut Seni Indonesia (ISI) Denpasar \\ Jalan Nusa Indah, Denpasar 80235 \\ Email: srinatih@gmail.com
}

\begin{abstract}
In the discourse of performing art creations, there is an assumption that creating art works is not categorized as a scientific, based on a personal taste and instinctive. This article uses a qualitative research with the performing arts approach. By using ethnographic methods, this article focuses on the role of performers in the process of creating the performing arts. Data are collected through interviews, library research, and document studies. As an object of study, 5 (five) outstanding works will be discussed, namely: Terompong beruk (1982), Bali Agung (2010), Ratricetana (2011), Terompong beruk Bangkok (2015), and Stri wiroda (2015). The results of this study indicate that the models of creative as parts of important processes in creating performances are diverse. Through researching creative processes of the works, performers can create new type of works that are different from others, and distinctive from previous works. The novelty of the creative processes contains the quality of aestethic in forms and contents, as well as their values and functions.
\end{abstract}

Keywords: research, creative processes, new creations, performing arts

\begin{abstract}
ABSTRAK
Dalam pewacanaan hasil penciptaan seni pertunjukan, masih ada anggapan bahwa menciptakan karya seni itu sesuatu yang tidak ilmiah dan hanya berdasarkan selera dan insting belaka. Artikel ini merupakan hasil penelitian kualitatif dengan pendekatan seni pertunjukan, dengan menggunakan metode etnografi, dengan fokus pada pencipta/seniman seni pertunjukan. Data-data yang dikumpulkan didapat melalui observasi, wawancara, riset kepustakaan, dan studi dokumen. Sebagai objek kajian, akan dibahas 5 (lima) buah karya cipta seni pertunjukan yang berbasis penelitian, yaitu: Terompong Beruk (1982), Bali Agung (2010), Ratricetana (2011), Terompong Beruk Bangkok (2015), dan Stri wiroda (2015). Adapun hasil dari kajian ini menunjukkan bahwa model proses kreatif yang sangat penting dalam penciptaan seni pertunjukan itu sangat beragam. Melalui penelitian mengenai kajian proses kreatif tersebut dapat dihasilkan karya seni pertunjukan kreasi baru yang berbeda satu sama lain, dan berbeda dari proses kreatif karya sebelumnya. Nilai kebaruan proses kreatif itu mengandung keindahan bentuk dan isi, serta nilai dan fungsinya.
\end{abstract}

Kata kunci: penelitian, proses kreatif, penciptaan, seni pertunjukan 


\section{PENDAHULUAN}

Penelitian merupakan salah satu aspek penting dari Tri Dharma Perguruan Tinggi, yang meliputi Pendidikan, Penelitian, dan Pengabdian Kepada Masyarakat. Tanpa adanya penelitian sudah tentu Tri Dharma Perguruan Tinggi itu tidak akan berjalan dengan sempurna serta sangat sulit dibayangkan kualitas yang dihasilkan oleh sebuah perguruan tinggi. Oleh karena itulah, sebagai institusi dalam masyarakat modern, perguruan tinggi seni harus mampu secara terus menerus mendorong adanya inovasi-inovasi dalam bidang keilmuan seni yang menjadi konsentrasinya. Sebagaimana dinyatakan dalam Higher Education Long Terms Strategy (HELTS, 2003-2010) bahwa perguruan tinggi didorong dan dibina agar dapat meningkatkan kualitasnya untuk peningkatan daya saing bangsa. Perguruan tinggi seni merupakan bagian dari masyarakat akademis yang harus mampu melakukan penelitian yang berkualitas dan berkelanjutan. Penelitian itu sendiri tidak saja penting dalam konteks pengkajian objek seni, tetapi menjadi aspek yang sangat mendasar dalam penciptaan karya seni. Penciptaan seni yang berbasis penelitian akan dapat memberikan pemahaman yang mendalam kepada penggarapnya tentang karya seni yang akan diciptakannya.

Sampai saat ini, masih terdapat masalah berupa anggapan masyarakat awam dan masyarakat bidang non-seni, bahwa penciptaan karya seni pertunjukan itu adalah hal yang gampang, tidak ilmiah, berbasis pada selera dan insting sesaat yang dikenal dengan istilah "kleteg" (di Bali). Oleh karena itulah, studi tentang penciptaan seni pertunjukan yang berbasis penelitian sangat perlu dan mendesak untuk dilakukan.

Dalam paper ini akan dibahas lima buah karya seni yang berbasis penelitian, yaitu Terompong Beruk 1982, Ratricetana, Bali Agung - The Legend of Balinese Goddesses (2010), Terompong Beruk Bangkok 2015 (TBB 2015), dan Stri wiroda (2015).

\section{METODE}

Penelitian ini adalah penelitian kualitatif. Metode kualitatif memanfaatkan cara penafsiran dengan menyajikannya dalam bentuk deskripsi (Ratna, 2009: 46). Demikian juga dalam penelitian ini, yaitu mengenai seni pertunjukan ciptaan baru yang berbasis penelitian (riset), peneliti di sini mengungkap nilai dan fungsi di balik bentuk dan wujud karya seni pertunjukan yang disajikan dalam bentuk deskripsi melalui intepretasi fenomena proses kreatif penciptaan karya seni yang terjadi di lapangan.

Dalam penelitian kualitatif, peneliti merupakan instrumen utama dalam mengumpulkan data. Data dikumpulkan melalui wawancara, observasi, studi kepustakaaan, dan dokumen. Peneliti terjun langsung ke lapangan untuk melakukan wawancara kepada informan. Dalam melakukan wawancara, informan diberitahu maksud dan tujuan wawancara serta penggunaan alat perekam selama wawancara berlangsung. Hasil wawancara itu dikumpulkan, diinterperetasikan, dan dianalisis sesuai kebutuhan penelitian dengan menggunakan teori intepretasi (Poespoprodjo, 1987) sebagai alat bedah analisisnya.

Proses intrepretasi itu mencakup tiga tahapan, yaitu (1) meng-kata-kan (membahasakan atau mendeskripsikan dengan bahasa ilmiah yang lugas dan jelas); (2) Menerangkan berdasarkan realitas temuan pada pembahasaan tadi; dan (3) menerjemahkan dari korelasi-korelasi yang dibangun dari deskripsi objek, arti, fungsi dan makna yang diperolehnya.

\section{HASIL DAN PEMBAHASAN}

\section{Seni Pertunjukan Berbasis Penelitian}

Seni pertunjukan berbasis penelitian dapat dipahami sebagai sebuah karya seni pertunjukan yang dalam proses penciptaannya diawali dengan sebuah penelitian (riset). Setelah data-data yang dikumpulkan dianggap cukup, maka penggarap 
akan merangkumnya menjadi sebuah skenario sesuai dengan konsep garapan yang diinginkan. Berdasarkan skenario yang dibuat, selanjutnya diimplementasikan melalui proses penggarapan tahap demi tahap sehingga menghasilkan sebuah bentuk seni pertunjukan sesuai yang diinginkan (Rai, 2015). Dalam bidang seni pertunjukan, wujud dari garapan itu dapat berupa seni tari, seni karawitan (musik), seni pedalangan (teater), atau bisa juga merupakan sebuah kolaborasi yang mencakup semua unsur dari seni pertunjukan itu sendiri. Dalam hubungan ini, kata kuncinya adalah garapan itu berbasis penelitian (riset), bukan selera dan insting sesaat yang dikenal dalam istilah Bali sebagai sistem kleteg.

Rai (2015), mengungkapkan dalam papernya yang berjudul "Implementasi 'lokal-global' pada Institusi dan Karya Seni", bahwa kreativitas dalam penciptaan sebuah karya seni khususnya di Perguruan Tinggi Seni seperti ISI Denpasar, maupun perguruan tinggi seni lainnya, sudah seyogyanya didasarkan hasil penelitian yang disebut dengan istilah research based creativity (kreativitas berbasis riset). Karya seni yang dilandasi dengan riset itulah yang menjadi salah satu ciri dari "karya seni akademis" yang dihasilkan oleh para insan akademis. Lebih jauh, dalam paper itu ditegaskan bahwa kualitas garapan Tugas Akhir untuk tingkat sarjana (S1) dan pascasarjana (S2 dan S3) sangat tergantung dari kedalaman riset yang dilakukan serta daya kreativitas penggarapnya.

\section{Karya 1. Terompong Beruk (1982)}

Terompong beruk adalah sebuah karya musik kontemporer yang digarap oleh I Wayan Rai S. pada tahun 1982. Karya ini diilhami sebuah instrumen musik tunggal yang bernama terompong beruk yang terdapat di Desa Abang, Kabupaten Karangasem, Bali. Menurut penjelasan Rai (wawancara 12 September 2015), penelitian tersebut dilatarbelakangi adanya undangan dari panitia Pekan Komponis Muda di Taman Ismail Marzuki, Jakarta. Dalam rangka mempersiapkan garapan yang akan ditampilkan pada Pekan Komponis Muda tersebut, Rai berusaha mencari ide melalui riset kepustakaan (library research). Ketika mengunjungi Perpustakaan Mudra Swara di Puri Mas, Ubud, Rai menemukan buku berjudul Music in Bali karya Collin McPhee (1966). Pada bagian illustration \#75 dari buku itu terdapat foto hitam-putih mengenai instrumen terompong beruk yang sedang dimainkan dalam barungan gamelan Angklung di Desa Abang, Karangasem, Bali. Rai sangat tertarik dengan terompong beruk tersebut sebab namanya saja baru pertama kali diketahuinya, serta instrumen itu belum pernah dilihatnya. Selanjutnya, Rai memutuskan untuk menggarap terompong beruk itu untuk dipersembahkan pada Pekan Komponis Muda 1982 di Jakarta. Gagasan dari seniman tersebut adalah bagaimana caranya mengangkat kesenian yang langka atau telah punah, menjadi sebuah garapan ciptaan baru baik yang berbasis tradisi dan dengan sentuhan kekinian (kontemporer).

Sehubungan dengan itu, pada bulan Februari 1982, Rai langsung melakukan riset ke Desa Abang dan tinggal selama seminggu di Banjar Magetelu, Abang, Kabupaten Karangasem, Bali. Rai menginap di rumah bapak I Nyoman Karang, seorang seniman ternama di Desa Banjar Magatelu yang banyak mengetahui tentang eksistensi kesenian di daerah Karangasem. Berkat bantuan bapak I Nyoman Karang beserta keluarganya, Rai diperkenalkan dengan beberapa seniman yang memiliki pengetahuan dan ikut sebagai pemain terompong beruk sekitar tahun 1940-an.

Dari informasi yang berhasil dikumpulkan, dapat diketahui bahwa terompong beruk itu pada mulanya adalah sebuah instrumen tunggal, bilahnya terbuat dari ruyung dengan resonator dari beruk (ba- 
tok kelapa) dengan teknik permainan terompong sebagaimana teknik permainan terompong pada gamelan gong gede. Oleh karena itulah instrumen tunggal itu disebut terompong beruk. Sebagai karya seni instrumen tunggal yang berlaras pelog atau slendro, Terompong beruk dimainkan secara improvisasi oleh petani ketika melepas lelah di sawah. Dalam perkembangan selanjutnya, selain dimainkan secara improvisasi di sawah, terompong beruk juga dimasukkan sebagai bagian dari instrumen gamelan angklung yang berlaras slendro empat nada di Desa Abang. Untuk itu, secara khusus dibuat instrumen Terompong beruk berlaras slendro empat nada sesuai dengan laras dari barungan gamelan angklung tersebut.

Menurut penjelasan Rai, dalam penelitian tentang terompong beruk itu, dia datang ke Desa Abang beberapa kali, dan setiap kali datang dia tinggal di sana selama tiga sampai tujuh hari. Selama mengadakan penelitian, Rai juga melakukan pengamatan di areal persawahan dan suasana desa mulai dari pagi hingga larut malam. Hal itu dilakukan agar mendapatkan inspirasi dari nuansa persawahan serta nuansa pedesaan yang akan diekspresikan ke dalam garapannya. Setelah data yang didapatkan cukup, maka Rai menuangkannya ke dalam konsep garapan.

Secara garis besar, konsep garapan itu terdiri atas: judul garapan, tema garapan, bentuk garapan, instrumentasi, pemain, tata busana, setting, tata suara dan tata lampu, serta durasi garapan. Rai memutuskan bahwa judul garapan yang akan ditampilkan pada Pekan Komponis Muda 1982 di Taman Ismail Marzuki, Jakarta adalah terompong beruk. Judul garapan itu ditetapkan karena terompong beruklah yang menjadi sumber inspirasi pertama dan utama dalam garapan itu. Karena terompong beruk itu pada kenyataannya dimainkan di sawah dengan suasana pedesaan yang kental di
Magetelu Karangasem, maka Rai ingin menjadikan suasana itu sebagai tema pokok yang dapat dijadikan referensi utama dalam membuat garapan baru.

Bentuk garapan yang direncanakan adalah sebuah garapan kontemporer (kekinian) yang bersumber dari tradisi. Garapan itu lahir sesuai dengan pandangan (point of view) serta interpretasi estetis penggarapnya. Bermula dari instrumen terompong beruk, maka dalam hal instrumentasi untuk garapan ini, Rai mengembangkan isntrumen-instrumen baru yang tidak lazim seperti reong yang terbuat dari batok kelapa, kendang daribambu, kepuakan (sejenis penghalau burung terbuat dari potong bambu), guwetan (potongan bambu kecil yang diikat dengan sutas tali lalu dimainkan dengan cara memutar sehingga mengeluarkan bunyi), sapu lidi, dan suling somi (seruling dengan bahan batang padi). Dalam prakteknya, permainan instrumen yang menjadi semacam barungan terompong beruk, masih ditambah lagi dengan ilustrasi suara anjing yang dilakukan oleh pemain musik dengan jalan menirukan suara anjing, suara burung dengan seruling, serta suara angin dengan guwetan. Proses ekplorasi dan eksperimentasi pencarian model instrumenintrumen baru yang disesuaikan dengan konsep dan bentuk alat tersebut adalah tindakan riset. Hal ini sama seperti dilakukan dalam riset penciptaan intrumen-intrumen baru karya seniman Dodong Kodir (Hendriyana, 2008).

Garapan terompong beruk ini didukung oleh 17 orang pemain putra dan putri. Setiap pendukung ditugaskan untuk memainkan dua sampai tiga jenis instrumen yang berbeda. Untuk mendukung dan menggarisbawahi suasana pedesaan dan persawahan, maka garapan ini diisi ilustrasi tembang Bali di mana teks dari tembang tersebut menggambarkan suasana yang diinginkan misalnya ngedes lemah (pagi hari), suasana di sawah pada saat petani bekerja, 
serta suasana terkait lainnya. Beberapa pemain memakai busana keseharian seperti apa adanya di desa Abang, dan ada juga yang memakai kostum petani untuk menguatkan karakter masing-masing.

Dalam pementasannya di Taman Ismail Marzuki, setting dibuat sesuai panggung tapal kuda dengan instrumen terompong beruk serta kepuakan menjadi titik sentral (fokus). Pemain serta instrumen yang lain dibuat bergerak dari satu posisi ke posisi yang lain dengan sentuhan teatrikal. Untuk tata suara, secara sengaja tidak dibantu oleh microphone dengan maksud agar suara yang dihasilkan oleh instrumen dan vokal sesuai dengan aslinya mengingat posisi penonton yang sangat dekat dan menyatu (intimate). Sedangkan untuk tata lampu (lighting) diatur sedemikian rupa agar dapat menggambarkan suasana di pagi, siang, dan malam hari sebab yang digambarkan dalam garapan itu adalah siklus dari pagi sampai malam.

Perlu dipahami bahwa untuk dapat mewujudkan garapan sesuai keinginan komposernya, maka sebelum proses penggarapan dilakukan, beberapa orang pemain inti diajak melakukan observasi ke Desa Abang guna mendapatkan suasana desa setempat. Mereka juga diajak menginap di Desa Abang agar dapat mengalami suasana pagi, siang, dan malam baik di sawah maupun di desa. Cara tersebut ternyata sangat membantu para pemain dalam usaha untuk menginterpretasikan serta mengekspresikan keinginan penggarap.

Akhirnya, setelah mengalami proses penggarapan selama tiga minggu, maka garapan baru itu dipentaskan secara perdana di Taman Budaya Denpasar, dengan disaksikan para mahasiswa, dosen, seniman, budayawan, serta kritikus seni. Setelah pementasan selesai, kemudian diadakan diskusi antara penggarap dan undangan untuk mencari masukan agar pertunjukan di Jakarta lebih baik lagi. Selanjutnya, sesu- ai dengan jadwal yang ditetapkan panitia Komponis Muda Jakarta maka terompong beruk berhasil dipentaskan di teater Arena, Taman Ismail Marzuki pada tahun 1982.

Riset serta rekonstruksi terompong beruk yang dilakukan Rai pada tahun 1982, ternyata telah memberi dampak kepada seniman dan pemerintah daerah Kabupaten Karangasem. Para seniman di Desa Abang dan sekitarnya mulai menghidupkan kembali terompong beruk yang konon pernah ada di daerah tersebut. Mereka membuat barungan terompong beruk yang dilengkapi dengan tari-tarian. Pemerintah Daerah Kabupaten Karangasem pun ikut memotivasi seniman dan masyarakat untuk terus menggali kekayaan budaya yang telah punah. Pemkab Karangasem bahkan menyatakan bahwa terompong beruk adalah "kesenian khas" Karangasem. Seniman Karangasem sangat bangga akan hal tersebut dan mampu menampilkan beberapa sekaa (organisasi, grup) terompong beruk pada Pesta Kesenian Bali di Taman Budaya Denpasar.

Karya 2. Terompong Beruk Bangkok (2015)

Dalam perkembangan selanjutnya, setelah berselang 33 tahun terompong beruk ditampilkan di Taman Ismail Marzuki Jakarta, maka tanpa diduga Rai mendapat undangan untuk menampilkan sebuah garapan kontemporer di Bangkok dalam even internasional yang diadakan oleh SEAMEOSPAFA. Kegiatan internasional tersebut bertajuk Spiritual Dimensions of Rice Culture in Southeast Asia (Seminar, Ritual, and Performance). Untuk kepentingan even internasional tersebut, Rai yang bergabung dengan rombongan ISI Denpasar, menampilkan karya yang diberi judul Terompong beruk Bangkok 2015. Dilihat dari judul garapannya sudah sangat jelas bahwa Rai ingin menggarap kembali terompong beruk versi yang baru. Dalam garapan terompong beruk versi baru ini Rai menambahkan beberapa orang penari lagi untuk memerankan be- 
berapa karakter seperti Dewi Sri, kodok, itik, burung, dan lelakut (orang-orangan). Menurut penjelasan Rai, penggarapan terompong beruk dengan versi yang baru itu didasarkan pertimbangan bahwa tema dari even yang diadakan oleh SEAMEO-SPAFA tersebut berkaitan dengan budaya padi, dan terompong beruk itu sendiri merupakan instrumen yang sangat erat konteksnya dengan kehidupan petani di sawah.

Terompong Beruk Bangkok 2015 (disingkat TBB 2015) merupakan sebuah garapan kontemporer yang berbasis kearifan lokal Bali. Dalam tulisarnya yang berjudul "Agriculture as a Source for Artistic Creativity: Terompong Beruk Bangkok 2015", Rai menjelaskan bahwa proses kreatif dari TBB 2015 terdiri atas empat tahap yaitu: ide, $n u$ asen, penuangan ide, dan gladi bersih atau pementasan (lihat, Srinatih, 2014: 79-94).

Terkait dengan ide garapan, Rai (2015:

2) menjelaskan sebagai berikut:

"the idea is still the same with the first composition which is inspired by a single instrument named terompong beruk. Inspired by this instrument, the idea grows into the desire to express Balinese agriculture into a contemporary composition. This contemporary composition is based on the composer's point of view, is highly subjective, often instantaneous change, and is based on the composer's background. In other words, the composition is a reflection of the composer... the idea continues to grow in accordance with the place, time, and circumstances [Bali: desa, kala, patra] ..."

Setelah ide garapan didapatkan maka dilanjutkan dengan upacara nuasen, yaitu hari baik untuk memulai latihan. Upacara nuasen dilakukan di Pura Padmanaraswara ISI Denpasar dengan jalan melakukan persembahyangan bersama pendukung garapan dengan harapan garapan yang direncanakan akan berhasil dengan baik serta memiliki taksu (inner power). Setelah persembahyangan selesai, penggarap memberikan penjelasan kepada semua pendukung agar mereka memiliki persepsi yang sama.
Setelah upacara nuasen selesai, dilanjutkan dengan penuangan garapan secara bertahap dan berkelompok sesuai dengan tugas masing-masing pendukung. Latihan sektoral dilakukan di dua tempat yaitu di kampus ISI Denpasar dan di rumah penggarap yang beralamat di Perum ISI Denpasar, Jalan Raya Angantaka-Kutri, Abiansemal Badung. Setelah melakukan beberapa kali latihan gabungan maka garapan TBB 2015 dapat terwujud. Gladi bersih dilaksanakan di gedung Natya Mandala ISI Denpasar pada tanggal 30 April 2015.

Pementasan TBB 2015 di Bangkok dilaksanakan pada tanggal 12 Mei 2015 dengan mengambil tempat di Asok Montri Performing Art Hall 14th floor. Struktur dari TBB 2015 terdiri atas tiga bagian yaitu: bagian pertama disebut ngedeslemah (early morning), bagian kedua Uma sadina (daily activities in the rice field), dan Lelakut Ngigel (scarecrow dancing). Struktur garapan ini didasarkan atas kearifan lokal Bali yang disebut Tri angga yaitu tiga bagian utama dari tubuh manusia yang terdiri atas kepala, badan, dan kaki (Rai, 2015: 4).

Karena TBB 2015 merupakan sebuah garapan kontemporer maka Rai membuat outline garapan secara garis besarnya saja. Hal itu disebabkan karena Rai ingin memberikan kesempatan kepada para pendukung garapan untuk merespon lingkungan dimana garapan itu dipentaskan. Ketiga bagian (tri angga) dari struktur garapan TBB 2015 dapat dilihat pada table 1.

Perlu dipahami bahwa dalam garapan TBB 2015, Rai memasukkan beberapa konsep kearifan lokal Bali, misalnya tri angga, rwa-bhineda, menyama braya, desa-kala-patra, dan tri hita karana. Konsep tri angga (kepala, badan, dan kaki) terefleksi dari struktur garapan yang terdiri atas ngedeslemah, uma sadina, dan lelakut ngigel. Konsep rwa bhineda (dualisme) misalnya tergambar dari pendukung yang berjenis kelamin laki-perempuan, lelakut laki-perempuan, 
Tabel 1. Bagian (tri angga) terompong beruk Bangkok 2015

\begin{tabular}{|c|c|c|}
\hline Pembabakan & Adegan & Keterangan \\
\hline Kawitan & $\begin{array}{l}\text { ngedes } \\
\text { lemah } \\
\text { (dini } \\
\text { hari) }\end{array}$ & $\begin{array}{l}\text { Diawali dengan su- } \\
\text { ara genta dan vo- } \\
\text { kal, muncul Dewi } \\
\text { Sri, menari secara } \\
\text { improvisasi. }\end{array}$ \\
\hline \multicolumn{3}{|c|}{ Transisi } \\
\hline Pengawak & $\begin{array}{l}\text { uma sadi- } \\
\text { na (kegi- } \\
\text { atan se- } \\
\text { hari-hari } \\
\text { di persa- } \\
\text { sawahan) }\end{array}$ & $\begin{array}{l}\text { Masuk suara kron- } \\
\text { congan sapi (call and } \\
\text { respond), dialog } 2 \\
\text { orang petani (laki } \\
\text { dan perempuan), } \\
\text { dilanjutkan de-- } \\
\text { ngan Pupuh Ginada } \\
\text { Linggar Petak yang } \\
\text { diiringi suara batu, } \\
\text { genjek dan instru- } \\
\text { ment lain. Selain } \\
\text { itu, ada tarian yang } \\
\text { mengikuti gerakan } \\
\text { padi, bebek, dan } \\
\text { katak yang disertai } \\
\text { suara enggung. }\end{array}$ \\
\hline \multicolumn{3}{|c|}{ Transisi } \\
\hline Pengecet & $\begin{array}{l}\text { lelakut } \\
\text { ngingel } \\
\text { (Orang- } \\
\text { orangan } \\
\text { sawah } \\
\text { menari) }\end{array}$ & $\begin{array}{l}\text { Lelakut lelaki me- } \\
\text { nari dan lelakut } \\
\text { perempuan menari } \\
\text { secara improvisasi, } \\
\text { tempo perlahan } \\
\text { naik, ada badai dan } \\
\text { kekacauan, dan } \\
\text { akhirnya lelakut } \\
\text { dan semua penari } \\
\text { jatuh. }\end{array}$ \\
\hline
\end{tabular}

Sumber: Data diolah dari I Wayan Rai S. (2015)

serta teknik permainan kotekan (interlocking figurations) yang terdiri atas polos dan sangsih. Konsep menyama braya sebagai refleksi kebersamaan tergambar dari suasa gotong royong para petani. Konsep desa-kala-patra (tempat, waktu, dan keadaan) telah menjadi landasan dari garapan ini sehingga penampilannya di Bangkok agak berbeda dengan penampilan pada saat gladi bersih di ISI Denpasar. Terakhir, konsep tri hita karana yang menekankan keharmonisan antara manusia dengan Tuhan, manusia dengan sesama manusia, dan manusia dengan lingkungan, tergambar dari pesan dalam pertunjukan secara menyeluruh yang pada dasarnya selalu menekankan keharmonisan (Rai, 2015: 5).

Singkatnya, terompong beruk yang dipentaskan pada Pekan Komponis Muda di TIM Jakarta pada tahun 1982 dan Terompong beruk Bangkok 2015, dapat diwujudkan setelah melalui proses penelitian yang panjang. Keduanya merupakan garapan kontemporer tetapi memiliki bentuk yang berbeda sesuai dengan point of view (pandangan) penggarapnya.

\section{Karya 3. Ratricetana (2009)}

Ratricetana adalah sebuah garapan kontemporer dan berbasis interpretasi on the spot (spontanitas ditempat pementasan) dari sebuah kidung yang bernama $P u h R a-$ tricetana. Garapan ini bersumber dari hasil penelitian yang berjudul Lontar Kidung Gambang Gita Gegrantangan (Kawi-IndonesiaInggris), diterbitkan oleh ISI Denpasar tahun 2009. Penelitian ini merupakan sebuah penelitian kelompok, dengan ketua peneliti I Wayan Rai S. Anggota penelitinya terdiri atas: I Nyoman Suarka, Rinto Widyarto, Ni Ketut Dewi Yulianti, dan I Gde Agus Jaya Sadguna.

Dalam penelitian tentang Lontar Kidung Gambang Gita Gegrantangan, ditemukan adanya sembilan (9) jenis kidung dengan pola-pola metrum yang berbeda. Adapun kesembilan jenis kidung tersebut adalah: Puh Ratricetana, Puh Jayendriya, Puh Pengalang Sumaguna, Puh Manjangan Saluwang, Puh Rangga Kikis, Puh Langgarang, Puh Singhanalang, Puh Ukir Pandeglang, dan Puh Pamandana. Salah satu dari sembilan kidung yang berhasil ditemukan dalam penelitian tersebut bernama Puh Ratricetana, dengan struktur yang terdiri atas empat bagian yaitu: Kawitan bawak, Kawitan Panjang, Pangawak Bawak, dan Pangawak Panjang (Rai, dkk. 2009: 133-134).

Hasil penelitian tersebut dipaparkan pada Seminar Internasional (musik) vokal yang bertema Voice of the Archipelago dise- 


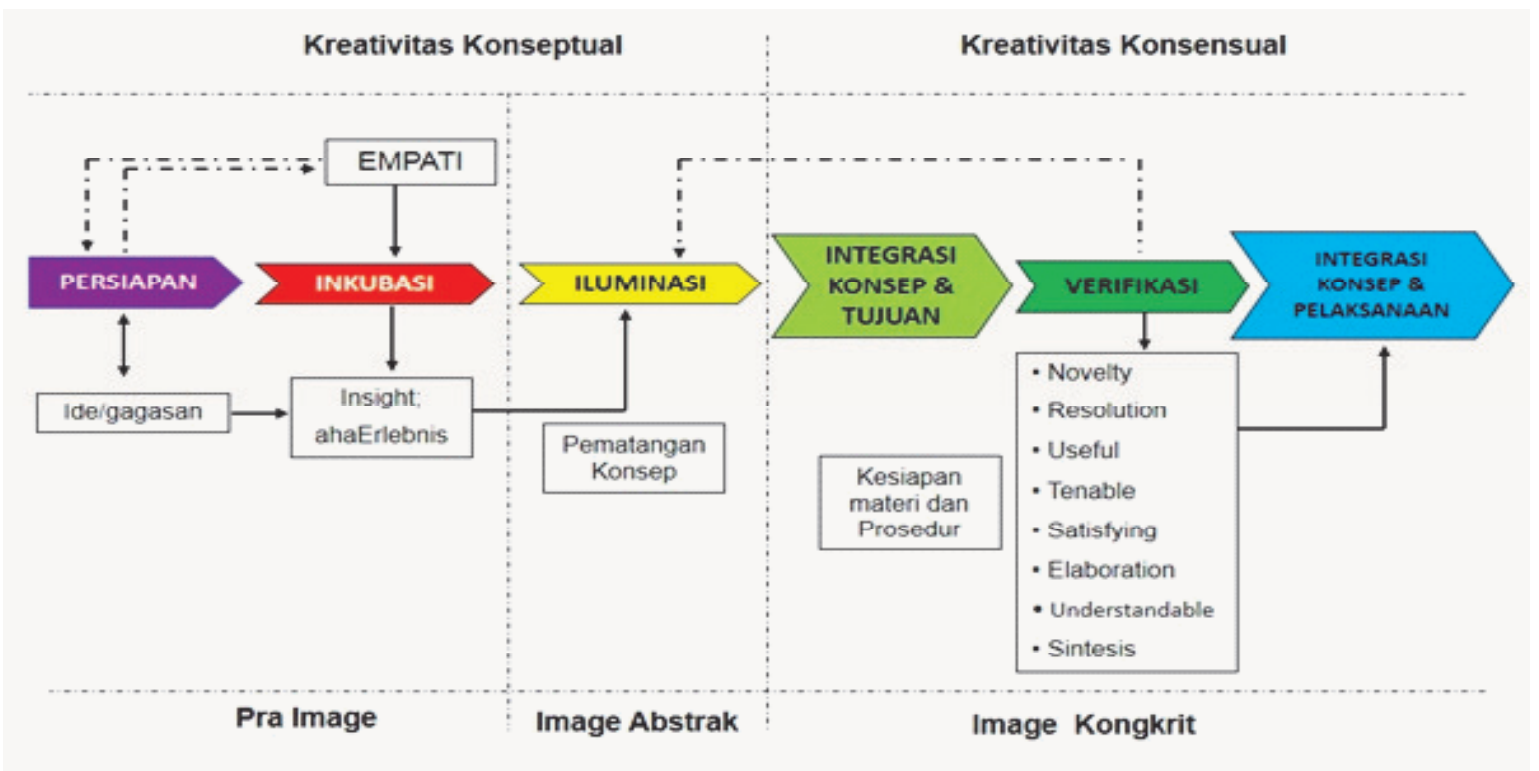

Bagan 1. Proses Kreatif (Hendriyana, 2008: 65)

lenggarakan dalam rangka Festival Kesenian Indonesia VII tahun 2011 di ISI Surakarta, Rai dan Suarka membawakan sebuah makalah yang berjudul Kidung as a Symbol of Life Cycle and a Source of Inspiration. Beberapa saat sebelum seminar internasional itu dimulai, Rai memiliki gagasan untuk melakukan presentasi dengan tambahan interpretasi secara spontan dengan dasar Puh Ratricetana yang bertema percintaan. Untuk itu Rai meminta bantuan Ni Ketut Suryatini dan Ni Komang Sekar Marheni untuk menyanyikan Puh Ratricetana; I Wayan Sutirta dan Anak Agung Mayun Artati menafsirkannya lewat tari, sementara itu I Wayan Setem diminta untuk mengekspresikannya ke atas kanvas. Kelima orang yang diminta menafsirkan sekaligus mengekspresikan Puh Ratricetana itu lewat vokal, gerak, dan goresan di atas kanvas, merupakan dosen ISI Denpasar.

Garapan Ratricetana itu dimulai dengan nyanyian vokal dari Suryatini dan Marheni, keduanya duduk di kursi peserta seminar dan berpakaian kasual sehingga tidak tertebak oleh penonton. Pandangan penonton yang tampak surprise (kaget) tertuju kepada kedua penyanyi. Sementara itu, Anak Agung Mayun Artati yang duduk di deret kursi nomor dua mulai menari sebagai tafsir dari isi teks Puh Ratricetana tersebut. Pada saat itu, perhatian penonton tampak terpecah; sementara itu I Wayan Sutirta yang juga duduk di kursi penonton bangkit dengan gerakan spontan dengan ekspresi berganti-ganti menafsirkan isi teks $P$ uh $R a$ tricetana. Dari tempat duduk masing-masing, kedua penari naik ke atas panggung dan melakukan gerakan duet yang menggambarkan percintaan. Sementara itu, I Wayan Setem sibuk dengan goresan yang merupakan ekspresi dari teks dan juga menggambarkan gerakan penari. Ketika Suryatini dan Marheni berhenti menyanyi, tiba-tiba penari dan pelukis juga berhenti beraktivitas, diam bagaikan patung.

Demikianlah, garapan kontemporer yang mendapat inspirasi dari Puh Ratricetana yang merupakan hasil dari sebuah penelitian, telah berhasil diwujudkan. Semua terjadi secara spontan tanpa adanya latihan. Rai hanya memberikan gambaran umum tentang apa yang diinginkannya. Akhirnya, terwujudlah sebuah garapan kontemporer dengan mengambil tempat di Teater Besar ISI Surakarta pada tanggal 14 Oktober 2011 (wawancara, 12 September 2015). Garapan karya kontemporer tersebut, tentu saja bu- 
kan karya yang spontan asal jadi, melainkan pengalaman estetik yang telah mengalami proses pengeraman ide dan pengorganisasian-pengorganisasian unsur proses kreatif tersebut, seperti yang tergambarkan pada bagan 1 mengenai alur proses kreatif (Hendriyana, 2008: 65).

\section{Karya 4. Bali Agung-The Legend of Balinese Goddesses}

Bali Agung - The Legend of Balinese Goddesses adalah sebuah seni pertunjukan wisata yang merupakan andalan dari Bali Safari \& Marine Park, yang berlokasi di daerah Lebih, Kabupaten Gianyar, Bali. Garapan Bali Agung ini merupakan sebuah garapan kolosal dan spektakuler dengan konsep yang meliputi akulturasi budaya (khususnya Bali-Cina), kolaborasi antarbudaya (intercultural collaboration), pemanfaatan teknologi terkini, mengangkat kearifan lo$\mathrm{kal}$, serta dikelola secara professional. Adanya seni pertunjukan ini juga untuk memperkuat pariwisata budaya yang melandasi pariwisata di Bali. Menurut Anggraeni Purnama Dewi (2016: 224-225), adanya wisata budaya bisa menjadi cara agar wisatawan lebih lama tinggal di suatu tempat wisata sehingga para wisatawan akan lebih banyak membelanjakan uangnya. Dengan begitu, para pelaku usaha dan masyarakat di sekitar destinasi tersebut semakin meningkat pendapatannya.

Proses garapan ini diawali dengan sebuah penelitian yang memakan waktu selama enam bulan (wawancara dengan I Made Sidia, 15 September 2015). Riset dilakukan oleh satu tim yang terdiri atas Peter J. Wilson (creative director), I Made Sidia (artistic director), Chong Lim (musical director), Richard Jeziorny (production designer), Ian Knowls (choreografer), Philip Lethlean (lighting designer), Collin Best (technical director), Sue Fenty (stage manager), Julia Smith (asst. stage manager) dan Richard Sam Pillai (animal trainer), dengan executive director ber- nama Hans Manansang. Setiap orang dari anggota tim telah diberikan tugas khusus sesuai dengan kompetensi dan tanggung jawab masing-masing.

Setelah mengadakan beberapa kali pertemuan, maka atas usul I Made Sidia, disepakati untuk mengangkat cerita yang berasal dari akulturasi kebudayaan Bali dengan Cina yang terjadi pada masa yang lampau. Langkah selanjutnya adalah melakukan pengumpulan data-data melalui riset perpustakaan, wawancara, melakukan kunjungan sekaligus observasi ke tempat-tempat yang terkait dengan Bali-Cina, menonton dan mencari model pertunjukan yang spektakuler, dan browsing lewat internet.

Riset kepustakaan dilakukan untuk mencari literatur yang menyangkut hubungan Bali-Cina seperti lontar Usana Bali dan Geguritan Sri Jaya Pangus. Wawancara dilakukan dengan dalang I Made Sija selaku pencetus dan pembina Sanggar Seni Paripurna, Bona, Gianyar, dan beberapa Pemangku Pura serta prejuru (pengurus) Pura Dalem Balingkang. Kunjungan ke tempat-tempat yang berhubungan dengan cerita Dalem Balingkang dilakukan ke sejumlah pura seperti Pura Dalem Balingkang, Pura Pucak Penulisan, dan Pura Batur. Ketiganya terletak di Kabupaten Bangli. Untuk mendapatkan model pertunjukan spektakuler maka secara khusus I Made Sidia melakukan observasi ke Bangkok, Thailand. Sementara itu, browsing lewat internet dilakukan secara intens dengan tujuan untuk mendapatkan gambaran yang komprehensif mengenai kostum. Hasil dari browsing ini penata kostum mendapat banyak insprirasi tentang kostum yang dipergunakan masing-masing karakter yang ada dalam garapan.

Setelah melakukan riset dan pendalaman selama enam bulan maka tersusunlah konsep garapan serta pembabakannya. Garapan baru yang akan diciptakan diberi judul, Bali Agung: The Legend of Balinese Goddeses. Karya seni ini mengisahkan tentang 
Tabel 2. Struktur pertunjukan Bali Agung

\begin{tabular}{|c|c|c|}
\hline No. & Adegan & Keterangan \\
\hline 1 & Pertama & Penggambaran suasana Bali yang sangat damai \\
\hline 2 & Kedua & $\begin{array}{l}\text { Kedatangan para saudagar Cina. Orang-orang Bali curiga bahwa kedatangan } \\
\text { mereka akan menimbulkan konflik, tetapi sebaliknya mereka sangat bersaha- } \\
\text { bat. Putri Kang Ching Wie diperkenalkan kepada Raja Jayapangus dan sang } \\
\text { raja langsung jatuh cinta kepada sang putri. }\end{array}$ \\
\hline 3 & Ketiga & $\begin{array}{l}\text { Upacara pawiwahan (perkawinan) anatara Raja Jayapangus dengan Kang Ching } \\
\text { Wie, yang sangat meriah dan mewah. }\end{array}$ \\
\hline 4 & Keempat & $\begin{array}{l}\text { Raja Jayapangus pergi ke hutan untuk bersemedi. Dalam perjalananya tiba-tiba } \\
\text { dia bertemu dengan Dewi Danu, maka terjadilah percintaan sampai melahir- } \\
\text { kan seorang anak laki-laki. Sebagai tanda kasih sayang, Raja Jayapangus mem- } \\
\text { berikan anaknya kalung yang merupakan kalung pada saat perkawinannya } \\
\text { dengan Kang Ching Wie. }\end{array}$ \\
\hline 5 & Kelima & $\begin{array}{l}\text { Kang Ching Wie gelisah dan menyusul suaminya ke tengah hutan tempat dia } \\
\text { semedi. Tiba-tiba Kang Chieng Wie bertemu dengan anak kecil. Alanghkah } \\
\text { terkejutnya Kang Chieng Wie karena mendapatkan anak kecil itu memakai } \\
\text { kalungnya Raja Jayapangus. Setelah ditelusuri ternyata anak itu adalah putra } \\
\text { dari Raja Jayapangus hasil hubungannya dengan Dewi Danu. Maka terjadilah } \\
\text { perang antara Kang Ching Wie yang diiringi prajurit dengan Dewi Danu de- } \\
\text { ngan prajurit para raksasa. Dalam perang ini Kang Ching Wie kalah. Kang Ching } \\
\text { Wie dan Raja Jaya Pangus akhirnya dikutuk oleh Dewi Danu menjadi batu }\end{array}$ \\
\hline 6 & Keenam & $\begin{array}{l}\text { Anak Dewi Danu menangis meminta agar ayahnya (Jayapangus) dan Kang Ching } \\
\text { Wie dihidupkan kembali. Namun usaha itu gagal, hanya arwahnya saja yang } \\
\text { datang. }\end{array}$ \\
\hline 7 & Ketujuh & $\begin{array}{l}\text { Anak Jayapangus dinobatkan menjadi raja, sementara itu untuk mengenang } \\
\text { Raja Jayapangus dan Kang Ching Wie, dibuatkanlah patung Barong Landung. } \\
\text { Tradisi Barong Landung, lanang-istri (laki-perempuan) sampai kini masih tetap } \\
\text { hidup di Bali. Sampai pada adegan ini, pementasan berakhir. }\end{array}$ \\
\hline
\end{tabular}

Sumber: Data diolah dari I Wayan Rai S. (2015)

liku-liku dan dinamika percintaan antara Raja Bali yang bernama Sri Jaya Pangus dengan seorang putri Cina yang bernama kang Ching Wie, serta kisah roman antara Jaya Pangus dengan Dewi Danu.

Pemilihan pendukung garapan, khususnya pemeran utama, dilakukan melalui audisi. Mereka yang terpilih sebagai pemeran utamanya adalah I Wayan Sira memerankan Raja Sri Jayapangus; Ni Wayan Sumariasih memerankan Kang Ching Wie; dan Made Ayu Desiari memerankan Dewi Danu. Para pendukung garapan lainnya yang jumlahnya berkisar antara 100-150 orang berasal dari Sanggar Paripurna Bona, dosen, mahasiswa, dan alumnus ISI Denpasar, ditambah beberapa orang seniman lokal lainnya (wawancara dengan I Made Sidia, I Made Sija, dan Made Ayu Desiari, 15 September 2015).
Selanjutnya, dilakukan proses penggarapan yang meliputi ide serta konsep garapan, nuasen, penuangan ide, dan latihan gabungan. Soft opening dari karya kolosal dan spektakuler ini berhasil dilaksanakan pada tanggal 29 Agustus 2010. Tempat pementasan Bali Agung telah dirancang secara khusus berupa sebuah stage yang diberi nama Bali theatre. Bali theatre adalah sebuah stage modern yang dilengkapi dengan tata lampu, tata suara, serta teknologi canggih lainnya sehingga mampu menampilkan sebuah pementasan yang spektakuler.

Pementasan Bali Agung diawali dengan parade para penari, penabuh, dan gajah untuk memberikan gambaran kepada penonton tentang tokoh-tokoh utama dalam garapan itu. Garapan kolaborasi ini berhasil memadukan berbagai unsur seni dan teknologi, termasuk diikutsertakannya 
beberapa jenis binatang seperti gajah, unta, ular, elang, dan harimau sebagai pendukung garapan. Setelah parade, dilanjutkan dengan pementasan Bali Agung dengan struktur pertunjukan sebagaimana dijelaskan pada table 2.

Pada awalnya, pementasan Bali Agung dilaksanakan tiga kali seminggu, yaitu pada hari Jumat, Sabtu, dan Minggu mulai dari jam 14: 30-15: 30 WITA. Dengan semakin membludaknya penonton yang menyaksikan Bali Agung, maka pementasannya kemudian dilaksanakan enam kali seminggu, mulai dari hari Selasa sampai dengan hari Minggu pada jam yang sama, yaitu 14: 3015: 30 WITA. Selain itu, garapan Bali Agung juga dipentaskan pada hari dan jam tertentu atas permintaan khusus.

Demikianlah, contoh dari seni pertunjukan yang berbasis riset yang melandasi ciptaan baru di atas, dengan judul Ratricetana dan Bali Agung - The Legend of Balinese Goddesses.

\section{Karya 5. Stri Wiroda}

Stri wiroda adalah sebuah tari kreasi baru ciptaan Made Ayu Desiari, seorang mahasiswi Jurusan Tari ISI Denpasar. Tari kreasi baru ini diciptakan dalam rangka memenuhi persyaratan Ujian Tugas Akhir untuk mencapai Gelar Sarjana Seni Strata 1 (S-1) pada tahun 2015.

Ide garapan ini muncul setelah Made Ayu Desiari (Dekyu) melihat salah satu fenomena yang mendapatkan perhatian besar dari publik, yaitu kasus-kasus kekerasan terhadap wanita. Fenomena-fenomena sosial yang terjadi seperti kasus pelecehan seksual, intimidasi, penistaan, kekerasan baik secara fisik maupun mental banyak dialami wanita dewasa ini (Desiari, 2015: 1-2). Terinspirasi oleh fenomena tersebut maka untuk mewujudkan idenya, langkah awal yang dilakukan Dekyu adalah melakukan penelitian dengan jalan pengumpulan datadata yang didapatkan melalui wawancara, observasi, penelitian kepustakaan, dan penelitian dokumen khususnya rekaman karya seni dengan tema yang sejenis.

Dari pengumpulan data-data tersebut didapatkan bahwa fenomena pelecehan terhadap wanita telah terjadi sejak masa yang lampau sebagaimana diceritakan dalam kitab Mahabharata pada bagian Sabha Parwa. Pada bagian ini dikisahkan bahwa para Pandawa yang dipimpin oleh Yudistira sedang bermain judi dengan Korawa. Semua kekayaan telah dipertaruhkan, hingga Yudistira mempertaruhkan istrinya, yaitu Dewi Drupadi. Dalam taruhannya yang tetakhir Yudistira kalah sehingga harus menyerahkan Dewi Drupadi kepada Duryodana. Dewi Drupadi diseret secara paksa oleh Dursasana sehingga kejadian tersebut memperlihatkan betapa wanita direndahkan dan dinistakan (ibid, hal. 2).

Berdasarkan hasil penelitian yang dilakukan, Desiari membuat sebuah garapan tari kreasi baru yang bersumber dari Wira Carita Mahabharata dengan judul Stri wiroda. Istilah Stri wiroda diambil dari bahasa Jawa Kuno dimana stri berarti istri, dan wiroda berarti kemarahan, permusuhan, pertengkaran, kehancuran (Mardiwarsito, 1986: 539, 688, dalam Desiari, 2015: 3). Dalam hubungannya dengan tari kreasi baru ini, Stri wiroda diartikan sebagai kemarahan seorang wanita, yaitu Dewi Drupadi yang disebabkan oleh perlakuan tidak senonoh yang dilakukan oleh pihak Korawa terhadap dirinya (ibid).

Tari kreasi baru Stri wiroda menggunakan struktur Tri angga yang terdiri atas Kawitan, Pangawak, dan Pangecet. Kawitan merupakan bagian awal yang menggambarkan kegelisahan Dewi Drupadi terhadap diri dan suaminya yaitu Pandawa; dan keharmonisan Pandawa dengan Drupadi di kerajaan Indraprasta. Pangawak merupakan bagian pokok dari tari ini yang menggambarkan kesiapan Pandawa menerima undangan untuk bermain dadu dengan Kora- 
wa, meskipun Pandawa mengetahui akan terjadi sesuatu dalam permainan tersebut. Terakhir, adalah pangecet yang menggambarkan sifat angkuh Korawa, suasana permainan dadu, pelecehan Dewi Drupadi oleh pihak Korawa yang menyulut kemarahan Dewi Drupadi (Desiari, 2015: 7-8).

Demikianlah garapan karya yang diawali dengan penelitian tersebut, nampaknya telah berhasil dipentaskan dan dipertahankan dalam ujian komprehensif, sehingga Made Ayu Desiari berhasil menyandang gelar Sarjana Seni (S. Sn.) di ISI Denpasar.

\section{SIMPULAN}

Berdasarkan uraian dan pembahasan di atas, dapat disimpulkan bahwa penelitian (riset) memegang peranan penting dalam penciptaan seni pertunjukan sebagaimana tercermin dari kelima garapan karya tersebut. Penciptaan seni pertunjukan berbasis penelitian terbukti dapat memberikan pemahaman yang lebih dalam serta menjadi referensi yang kuat dalam pembuatan skenario garapan. Setelah skenario berhasil diwujudkan maka dilanjutkan dengan proses penggarapan secara bertahap, sampai karya seni itu terwujud. Penciptaan berbasis penelitian yang telah dideskripsikan dalam tulisan ini, menghasilkan sejumlah model, sebagai berikut.

(1) Model proses kreatif dari karya Terompong beruk (1982) adalah sebuah garapan kontemporer yang terinspirasi oleh sebuah instrumen musik tunggal yang bernama terompong beruk. Tema dari musik ini adalah pedesaan, digarap sesuai dengan point of view (pendapat) komposernya. Dalam pementasannya garapan ini memakai konsep desa, kala, patra, yang berarti bahwa setiap pementasannya selalu memperhitungkan tempat, waktu, dan keadaan. Konsep desa, kala, patra, menyebabkan adanya fleksibilitas serta perubahan pada setiap kali garapan ini dipentaskan.
(2) Model proses kreatif dari karya Terompong beruk Bangkok 2015 adalah sebuah garapan Terompong beruk versi baru, dipentaskan dalam even yang bertajuk Spiritual Dimensions of Rice Culture in Southeast Asia, di Bangkok, Thailand. Tema kegiatan ini menyebabkan penggarapnya mendapat inspirasi baru, sehingga TBB 2015 sangat berbeda bentuk dan penampilannya dengan Terompong beruk yang dipentaskan di Jakarta tahun 1982. TBB 2015 mengangkat kearifan lokal Bali ke dalam garapan sehingga dapat memberi warna tersendiri pada garapan kontemporer ini.

(3) Model proses kreatif dari karya $R a$ tricetana adalah sebuah garapan kontemporer yang merupakan interpretasi on the spot (spontanitas ditempat pementasan) dari sebuah Kidung yang bernama Puh Ratricetana. Garapan yang bersumber dari hasil penelitian ini menggunakan tema percintaan. Sebagai sebuah garapan sesaat, Ratricetana memadukan unsur vokal, tari, dan lukis.

(4) Model proses kreatif dari karya Bali Agung (2010) adalah sebuah garapan kolosal dan spektakuler dengan perpaduan beberapa konsep seperti akulturasi budaya, kolaborasi internasional, pengangkatan kearifan lokal, perpaduan antara seni dan teknologi, serta dikelola secara professional sebagai salah satu bentuk seni tontonan wisata. Stage (tempat pementasannya) dibuat secara khusus dan permanen dengan fasilitas tata lampu, tata suara, serta property sesuai kebutuhan pementasan.

(5) Model proses kreatif dari karya Stri wiroda adalah sebuah garapan tari kreasi baru yang berbasis tradisi, diciptakan dalam rangka memenuhi salah satu Tugas Akhir (S1) di ISI Denpasar. Ide garapannya muncul dari fenomena sosial yang terkait dengan kasus-kasus kekerasan terhadap wanita yang banyak menjadi perhatian publik dewasa ini. Garapan ini juga diawali dengan sebuah penelitian, mengambil sumber ceritra dari Mahabharata khu- 
susnya bagian yang mengisahkan tentang pelecehan yang dilakukan pihak Korawa terhadap Drupadi setelah Pandawa kalah bermain judi. Pemanfaatan kearfifan lokal Bali ke dalam karya tari ini menyebabkan Stri wiroda dapat menyajikan keindahan bentuk serta isi.

Hasil penelitian ini membuktikan bahwa anggapan yang menyatakan penciptaan seni pertunjukan itu adalah masalah gampang, tidak ilmiah, dan hanya berdasarkan selera dan insting sesaat adalah tidak benar. Terkait dengan hal itu, penciptaan seni pertunjukan berbasis penelitian diharapkan dapat memotivasi serta menumbuhkan budaya riset dalam penciptaan seni sehingga menjadi salah satu model "karya seni akademis".

\section{Daftar Pustaka}

Dewi, A. P. (2016). Komodifikasi Tari Barong. di Pulau Bali (Seni Berdasarkan Karakter Pariwisata), Panggung, 26 (3), 222-233.

Higher Education Long Terms Strategy (HELTS) 2003-2010. (2010). Jakarta: Direktorat Jenderal Pendidikan Tinggi.

Duangwises, N. and Skar, L. D. (eds.), (2016). The Folk Performing Arts in ASEAN. Bangkok: Princes Maha Chakri Sirindhorn Anthropology Center.

Hendriyana, H. (2008). “Tinjauan Kreativitas pada Proses Penciptaan Alat Musik karya Dodong Kodir", Panggung, 18 (1), 54-66.
Srinatih, I. G. A. (2010). Representasi Dolanan Mabarong-barongan Kabupaten Badung Pada Pesta Kesenian Bali XXXII Tahun 2010 (Disertasi). Denpasar: Universitas Udayana.

Rai, I. W. S. (2015). Agriculture as a Source for Artistic Creativity: Terompong Beruk Bangkok 2015. Paper presented at the Seminar with the theme Spiritual Dimensions of Rice Culture in Southeast Asia. SEAMEO-SPAFA, Bangkok, 11-15 May 2015.

. (2015). Implementasi Lokal-Global pada Institusi dan Karya Seni. Paper pada Seminar Nasional dengan tema Seni dalam Glokalisasi, Program Pasca Sarjana, ISI Denpasar, 23 Juli 2015.

dkk. (2009). Lontar Kidung Gambang Gita Gegrantangan (Bali-Indonesia-Inggris). 2009. Denpasar: Institut Seni Indonesia.

Desiari, M. A. (2015). Skrip Karya Seni Stri Wiroda. (Skripsi), Program Studi S-1 Tari, Fakultas Seni Pertunjukan ISI Denpasar, Bali.

McPhee, C. (1966). Music in Bali: A Study in Form and Instrumental Organization in Balinese Music. New Haven: Yale University Press.

Poespoprodjo, P. (1987). Interpretasi. Bandung: Penerbit Remadja Karya.

Ratna, N. K. (2009). Teori, Metode, dan Teknik Penelitian Sastra. Yogyakarta: Pustaka Pelajar. 